DOE/ER/13580-F

Amendment M015

\title{
MECHANISMS AND CONTROLLING CHARACTERISTICS OF THE CATALYTIC OXIDATION OF METHANE
}

\author{
Kamil Klier, Gary W. Simmons, and Richard G. Herman \\ with \\ Kenneth T. Park, James S. Hess, Robert A. Hunsicker \\ Zettlemoyer Center for Surface Studies and Department of Chemistry, \\ Lehigh University, Bethlehem, PA 18015
}

Final Technical Report

Grant No. DE-FG02-86ER13580

Amendment No. M015

for the Period

September 15, 1996-February 14, 1999

Submitted to

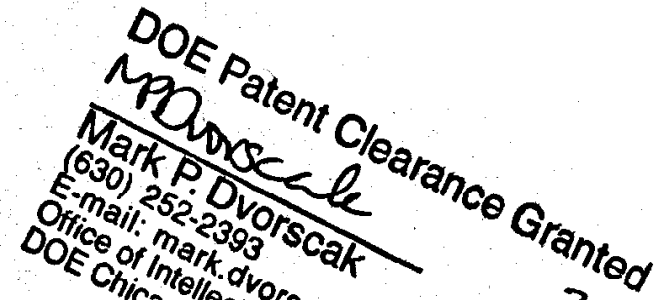

U. S. Department of Energy Office of Science

Basic Energy Sciences, Chemical Sciences Division

July 1999 


\section{DISCLAIMER}

This report was prepared as an account of work sponsored by an agency of the United States Government. Neither the United States Government nor any agency thereof, nor any of their employees, makes any warranty, express or implied, or assumes any legal liability or responsibility for the sccuracy, completeness, or use. fulness of any information, apparatus, product, or process disclosed, or represents that its use would not infringe privately owned rights. Reference berein to any specific commercial product, process, or service by trade name, trademark, manufacturer, or otherwise does not necessarily constitute or imply its endorsement, recommendation, or favoring by the United States Government or any agency thereof. The views and opinions of authors expressed herein do not necessarily state or reflect those of the United States Governmeat or any agency thereof. 


\section{DISCLAIMER}

Portions of this document may be illegible in electronic image products. Images are produced from the best available original document. 


\section{ABSTRACT}

Methane dissociation and oxygen activation have been found to be structure sensitive on different single crystal palladium surfaces. We have formed geometrically restricted surface ensembles on palladium single crystal and polycrystalline surfaces using tetrachloroethylene and pentamethylcyclopentasiloxane and have compared the observed surface structures with those previously obtained using dichloromethane and chlorine. We have also investigated the adsorption and activation of oxygen, carbon monoxide, and water on clean palladium surfaces and those containing the surface ensembles. To interpret high resolution angle-resolved X-ray photoelectron spectra (HR AR-XPS), a new self-modelling method of resolving HR-XPS spectra has been developed and applied to the experimental spectra. We have also investigated the effects of electron-accepting chlorine, oxygen, and water adsorbates on Cs-covered $\mathrm{MoS}_{2}$ by both HR AR-XPS and theoretical analyses. These studies are summarized in this report and described in detail in the following publications:

"Structure Sensitivity of Methane Dissociation on Palladium Single Crystal Surfaces," Klier, K., Hess, J. S., and Herman, R. G., J. Chem. Phys., 107, 4033-4043 (1997).

"Interaction of Tetrachoro-ethylene with $\mathrm{Pd}(100)$ Studied by High Resolution X-Ray Photoemission Spectroscopy," Park, K. T., Klier, K., Wang, C. B., and Zhang, W. X., J. Phys. Chem., 101, 5420-5428 (1997).

"Ensemble Effects in the Oxygen/Chlorine/Pd(100) System," Klier, K., Simmons, G. W., Park, K. T., Wang Y.-N., Hess, J. S., and Herman, R G., Langmuir, 14, 1384-1391 (1998).

"Adsorption of Pentamethyl-cyclopentasiloxane on the Pd(100) Surface Studied by High Resolution X-Ray Photoemission Spectroscopy," Park, K. T., Herman, R. G., and Klier, K., Surface Sci, 417, L1125-L1132 (1998).

"Electron Transfer Reactions on $\mathrm{Cs} / \mathrm{MoS}_{2}(0002)$ with Chlorine, Oxygen, and Water: High Resolution X-Ray Photoelectron Spectroscopy and Theoretical Study," Park, K. T., Hess, J. S., and Klier, K., L. Chem. Phys., 111, 1636-1649 (1999).

"A Self-Modeling Approach to the Resolution of XPS Spectra into Surface and Bulk Components," Simmons, G. W., Angst, D. L., and Klier, K., J. Electron Spectrosc. Relat. Phenom. (1999); in press.

"Dissociative Chemisorption of Pentamethylcyclopentasiloxane on a Palladium Foil," Hunsicker, R. A., Klier, K, and Herman, R. G.; under revision and to be submitted.

"XPS Resolution of Bulk and Surface Palladium Species by Self-Modeling of Angle Resolved Spectra of Palladium Foil after Pentamethylcyclopentasiloxane Adsorption," Hunsicker, R. A., Klier, K., and Simmons, G. W.; under revision and to be submitted.

"Electron Transfer and Redox Reactions on $\mathrm{Li} / \mathrm{MoS}_{2}(0002)$ with Chlorine, Oxygen, and Water: High Resolution X-Ray Photoelectron Spectroscopy and Theoretical Study," Park, $\mathrm{K}$. T., Klier, K., et al.; under revision and to be submitted. 


\section{Palladium Surfaces:}

Different Pd crystal faces have exhibited a significant structural anisotropy toward methane dissociation, and very large anisotropy to oxygen activation. This has significance for understanding oxidative conversions of methane. Potential energy surfaces (PES) have been constructed for methane dissociation on Pd crystals with the result that on Pd(111) the dissociation is nearly thermoneutral with a classical activation barrier $74 \mathrm{~kJ} / \mathrm{mol}$ that is penetrated by hydrogen to yield an effective activation energy of $56 \mathrm{~kJ} / \mathrm{mol}$ [1]. On defect planes [ $\mathrm{Pd}(679)$ and (311)], the reaction is exoenergetic, with thermodynamic driving force lowering the classical barrier, consistent with the Marcus Rule [1,2]. A quantitative model has been provided for structure sensitivity of $\mathrm{CH}_{4}$ dissociation not only on $\mathrm{Pd}$ but also on $\mathrm{Ni}$ [2], with the result that classical barriers are higher but tunneling effects are more pronounced on Pd than on Ni.

The formation of geometrically restricted surface ensembles and the concomitant electronic effects have been studied by a combination of dissociative chemisorption of chlorohydrocarbons, high resolution angle-resolved X-ray photoelectron spectroscopy (HR AR-XPS) in the core level and valence band regions, and theory. The adsorption and reaction of tetrachloroethylene $\left(\mathrm{C}_{2} \mathrm{Cl}_{4}\right)$ on a clean $\mathrm{Pd}(100)$ surface have been investigated at room and cryogenic temperatures [3]. Saturation of $\mathrm{Pd}(100)$ with $\mathrm{C}_{2} \mathrm{Cl}_{4}$ gas gave rise to a well-ordered $\mathrm{p}(2 \times 2)$ overlayer structure. HRXPS established that the $\mathrm{C}-\mathrm{Cl}$ bonds in the $\mathrm{p}(2 \times 2) \mathrm{C}_{2} \mathrm{Cl}_{4}$ overlayer were dissociated while retaining the stoichiometry $2 \mathrm{C}: 4 \mathrm{Cl}$, and the amounts of carbon and chlorine on the surface wre 0.125 and 0.25 monolayer (ML), respectively. At $131 \mathrm{~K}$, the exposure of the clean $\mathrm{Pd}(100)$ surface to $\mathrm{C}_{2} \mathrm{Cl}_{4}$ resulted in poredominantly molecular adsorption, evidenced by the binding energies (BEs) of the Cl2p and $\mathrm{Cls}$ core levels. A detailed core level scan in the $\mathrm{Cl} 2 \mathrm{p}$ region revealed two satellite $\mathrm{Cl}$ peaks: one shifted from the molecular $\mathrm{C}_{2} \mathrm{Cl}_{4}$ peak by $\triangle \mathrm{BE}=-2.7 \mathrm{eV}$ and the other by $\triangle \mathrm{BE}$ $=-1.4 \mathrm{eV}$, corresponding to atomic $\mathrm{Cl}$ and partially dissociated $\mathrm{C}_{2} \mathrm{Cl}_{4}$ species, respectively. As the temperature increased, the partially dissociated $\mathrm{C}_{2} \mathrm{Cl}_{4}$ gradually converted to adsorbed $\mathrm{Cl}$ atoms until $291 \mathrm{~K}$, at which temperature all $\mathrm{Cl}$ on the surface formed atomic $\mathrm{Cl}$ of 0.25 $\mathrm{ML}$ coverage. The carbon species, while present in stoichiometric amounts, did not give rise to additional structural features, but they indirectly affected the $\mathrm{Cl}$ ordering in forcing the $\mathrm{p}(2$ $x 2$ ) structure, which does not form upon dissociative adsorption of elemental chlorine [3]:

A further ensemble-controlling adsorbate was used in the form of adsorbed siloxane rings, initially five-membered pentamethyl pentamethylcyclopentasiloxane (PMPS). A new approach to ensemble control with a limiting aperture for access of molecules to the Pd surface has been demonstrated by chemisorption of the siloxane rings. On Pd(100), PMPS is strongly anchored through the formation of a $\mathrm{Si}-\mathrm{Pd}$ bond but the (-Si-O- $)_{5}$ rings retain their integrity [4]. Quantitative HRXPS analysis showed that the Si coverage corresponded to $0.74 \mathrm{ML}$. AR-XPS revealed a flat geometry of the siloxane ring and carbon from the methyl groups dissociated onto the Pd surface. Subsequent exposure of the PMPS-covered 
Pd surface to $\mathrm{CO}$ and $\mathrm{O}_{2}$ showed no adsorption of these molecules, demonstrating that the adsorbed PMPS completely blocked the metal surface. However, exposure to $\mathrm{Cl}_{2}$ gave rise to two distinct $\mathrm{Cl} 2 \mathrm{p}$ peaks in the HRXPS spectrum: a main component at $199.73 \mathrm{eV}$ and a much smaller peak shifted from the main peak by $\triangle \mathrm{BE}=-2.11 \mathrm{eV}$, corresponding to $\mathrm{Cl}$ atoms covalently bonded to PMPS and atomic $\mathrm{Cl}$ bonded to the Pd metal, respectively. Thus, $\mathrm{Cl}_{2}$ reacts with $\mathrm{PMPS}$ and the $\mathrm{Cl}$ atoms gain access to the $\mathrm{Pd}$ surface by rearranging the Cl/PMPS overlayer [4].

Chemisorption of PMPS has also been investigated on polycrystalline Pd foil [5]. The PMPS molecules dissociate upon adsorption onto the Pd foil and that a portion of the $\mathrm{Si}-\mathrm{O}$-Si bonds are cleaved, thereby destroying the cyclic nature of the compound. This resulted in the presence of three chemically different states of silicon at the Pd foil interface: Pd silicide, silicon carbide, and silicon oxide. Dramatic differences are found in the location of the $\mathrm{Si}$ and $\mathrm{C}$ species by using AR-XPS. The angular dependence of the photoemissions from the $\mathrm{Pd}$ foil revealed that dissociated $\mathrm{Si}$ atoms had diffused into the $\mathrm{Pd}$ foil and reacted to form a diluted Pd silicide layer estimated to be $12 \pm 2 \AA$ in thickness. This Pd silicide layer is located below a screening layer of approximately $8 \AA$. The screening layer is composed of a near-surface layer of silicon carbide, elemental carbon, and single-bonded silicon oxide species, and a surface layer of intact PMPS estimated to be $2.2 \AA$ in thickness. These results [5] show that the Pd foil reacts with PMPS in a significantly more complex manner than does single crystal $\operatorname{Pd}(100)$, which was shown to result in PMPS chemisorption retaining the integrity of the siloxane rings [4].

A new self-modelling method of resolving HR-XPS spectra for cases in which core level emissions are composed of multiple unresolved components has been developed [6]. This method has now been applied to resolving the AR-XPS spectra of PMPS on polycrystalline Pd foil [7], where non-linear screening factors were imbedded in the theory. The spectra were successfully resolved into angular dependent bulk and surface components without making assumptions about their line shapes. It was shown that the spectral components corresponded to a surface palladium silicide surface layer and the bulk Pd metal component, with the $P \mathrm{Pd}_{3 / 2}$ and $3 \mathrm{~d}_{5 / 2}$ peaks for the former being shifted $0.45 \mathrm{eV}$ to higher BEs relative to the latter bulk metal. Using an inelastic mean electron free path of $\lambda=32.53$ $\AA$ (for inorganic materials), a surface component thickness of $26.68 \AA$ was calculated [7]. This thickness for the surface component layer is consistent with an estimated thickness of $\approx 20 \AA$ A determined previously [5].

In our previous work with $\mathrm{Pd}(100)$, chemisorption of $\mathrm{CH}_{2} \mathrm{Cl}_{2}$ [8] and $\mathrm{C}_{2} \mathrm{Cl}_{4}$ [3] was found to be dissociative at room temperature and higher, forming very stable $\mathrm{Cl}$ overlayers. In the case of $\mathrm{CH}_{2} \mathrm{Cl}_{2}$, the dissociated chlorohydrocarbon overlayer was partially disordered, leaving enough space on the metal surface for oxygen chemisorption, and the surface carbon could be removed by reaction with the surface oxygen [8]. In contrast, the $\mathrm{C}_{2} \mathrm{Cl}_{4}$ molecules dissociated on $\operatorname{Pd}(100)$ into an ordered, fully saturated $p(2 \times 2)$ surface structure that contained $\mathrm{Cl}$ atoms and two-carbon residues, with no metal sites accessible to oxygen and 
from which the carbon fragments could not be removed by oxidation [3]. The presence of small surface concentrations of $\mathrm{Cl}$ from $\mathrm{CH}_{2} \mathrm{Cl}_{2}$ caused the oxygen to desorb at lower temperatures, indicating a weakening of the $\mathrm{O}-\mathrm{Pd}$ bond by lateral repulsion between the $\mathrm{Cl}$ and oxygen adatoms, and the range of this repulsion was over several Pd-Pd interatomic distances [8]. In separate experiments, photoelectron diffraction of surface core-level shifted Pd3d emission indicated that the O-Pd interaction extended over several Pd-Pd distances along the surface inward normal direction $[9,10]$. Those experiments suggested that the range of adsorbate interactions involving oxygen on Pd extends both laterally and into the metal beyond the nearest metal neighbors.

We subsequently examined the lateral interactions of reactive oxygen adatoms due to the presence of $\mathrm{Cl}$ on the surface of $\mathrm{Pd}(100)$, as well as the effect of the mobility or the lack thereof of both the $\mathrm{O}$ and $\mathrm{Cl}$ adsorbates on the behavior of the system [11]. The observed ensemble control of oxygen reactivity by immobile, partially ordered low coverage $\mathrm{Cl}$ overlayers has been cast into a statistical-mechanical model that quantitatively accounts for thermal programmed desorption (TPD) behavior with surface phase equilibria between a dense and a rare atomic oxygen phase [11]. It was shown that the $\mathrm{Cl}$ surface dopant exerts significant effects on the behavior of oxygen on the Pd metal surface at coverages $\left(\Theta_{C 1}\right)$ as low as $\Theta_{\mathrm{Cl}}=0.05$. The range of lateral $\mathrm{Cl}-\mathrm{O}$ interactions is estimated to be some two $\mathrm{Pd}-\mathrm{Pd}$ distances beyond and above the blocking of the fourfold holes and its nearest diagonal neighbors. This effect is attributed to the compression of the wanderer oxygen atom rare phase by restricting the free area for the oxygen atom mobility. The oxygen rare phase is in rapid equilibrium with the dense phase $\left(\Theta_{\mathrm{Cl}}=0.8\right)$, and compression of the rare phase by $\mathrm{Cl}_{(\mathrm{ads})}$ forces an adjustment of the relative concentrations of the two oxygen phases, thereby also indirectly affecting the low temperature sharp desorption from the dense phase. The surface analyses for $\mathrm{Cl}$ and $\mathrm{O}$, the $\mathrm{O}$ TPD, and the LEED patterns demonstrate that the $\mathrm{Cl}$ overlayer retains its coverage, distribution, and structure after cycling the system with oxygen up to $1000 \mathrm{~K}$. Thus, the $\mathrm{Cl}$ overlayers from $\mathrm{CH}_{2} \mathrm{Cl}_{2}$ display memory effects upon repeated oxygen adsorption-desorption cycles, showing that the ensemble control involves a permanent, partially ordered $\mathrm{Cl}$ structure [11].

A separate theoretical study of oxygen adsorption on Pd surfaces and its influence on XPS surface core-level peak shifts was carried out [12]. Theoretical calculations of surface core-level shifts of Pd3d induced by adsorbed oxygen were completed using the fullpotential linearized augmented plane wave density functional theory (FLAPW-DFT) method for periodic slab structures, involving both initital and final states [12], yielding results in agreement with experiment [10] to within $0.2 \mathrm{eV}$. 


\section{$\underline{M o S}_{2}$ Surfaces:}

Single electron transfer and reactivity were previously examined in the $\mathrm{Cs} / \mathrm{MoS}_{2}$ system by high resolution angle-resolved (AR) core-level [13] and valence band [14] XPS. Photoelectron diffraction features were separated from initial orbital shape effects, which have shown spatial anisotropy for emissions from the frontier valence orbitals that agree with theory [14]. The Cs6s electron was found to be located to $>90 \%$ in the Mo layer and was anisotropically screened in the photoemission process. A fundamental difference between ARXPS and ARUPS was found in observing signals averaged over many points of the surface Brillouin Zone in ARXPS while energy dispersion was observed in ARUPS. This feature assists significantly in the separation of diffraction phenomena from orbital shape effects.

That work has now been extended to the effects of electron-accepting adsorbates ( $\mathrm{Cl}$, $\mathrm{O}, \mathrm{H}_{2} \mathrm{O}$ ) on $\mathrm{Cs} / \mathrm{MoS}_{2}(0002)$ [15]. In particular, supra-valence electron transfer from surface Cs-doped $\mathrm{MoS}_{2}(0002)$ to electron acceptor adsorbates was investigated by high resolution $\mathrm{X}$-ray photoelectron spectroscopy (HRXPS) in the valence band region and above the valence band maximum (VBM). Deposition of a sub-monolayer amount of Cs onto the basal plane of $\mathrm{MoS}_{2}$ introduced a new electron density of state of $c a .1 .25 \mathrm{eV}$ about the VBM. Angle-resolved HRXPS and theoretical analysis located this electron density in the $\mathrm{MoS}_{2}$ layer. Upon the reaction with $\mathrm{Cl}_{2}$, this Cs-induced photoelectron almost completely disappeared and the Cs3d and Cl2p core levels indicated the formation of a surface Cschloride species.

The Cs-covered $\mathrm{MoS}_{2}(0002)$ surface also reacted at room temperature with $\mathrm{O}_{2}$ to form surface peroxides and superoxides, as evidenced by two distinct binding energies of the $\mathrm{Ols}$ core level peaks. In contrast the reaction with water proved to be more difficult. Exposure of the Cs-covered $\mathrm{MoS}_{2}(0002)$ surface to $\mathrm{H}_{2} \mathrm{O}$ at $10^{-5}$ Torr did not result in electron transfer reaction. However, the $\mathrm{Cs} / \mathrm{MoS}_{2}(0002)$ surface exposed to water at 1 Torr showed a substantial decrease in the density of states above the VBM, as well as formation of a surface hydroxide, indicated by the Ols core level position.

Theoretical calculations using a full-potential linearized augmented plane wave density functional theory (FLAPW-DFT) confirmed the conclusion based on experimental intensity anisotropy of the new peak that the Cs6s electron transfers into the $\mathrm{MoS}_{2}$ substrate, forming the $\mathrm{Cs} / \mathrm{MoS}_{2}$ electron-acceptor complex with $\mathrm{Cs}^{8+}$. The FLAPW-DFT calculations also showed the subsequent capture of the electron from $\mathrm{MoS}_{2}$ by surface $\mathrm{Cl}$, forming a twodimensional dispersed $\mathrm{Cs}-\mathrm{Cl}$ layer. The theory and experiment are in excellent quantitative agreement in predicting and observing the electron transfer from the $\mathrm{MoS}_{2}$ sheet to the electronegative molecular and atomic species [15]. 
The study of doped $\mathrm{MoS}_{2}$ has been continued with $\mathrm{Li} / \mathrm{MoS}_{2}$. This system is much more complex than is $\mathrm{Cs} / \mathrm{MoS}_{2}$. HR AR-XPS investigation indicates that $\mathrm{Li}$ diffuses into the interlayers of $\mathrm{MoS}_{2}$ and reduces part of the Mo [16].

\section{References:}

1. Klier, K., Hess, J. S., and Herman, R. G., "Structure Sensitivity of Methane Dissociation on Palladium Single Crystal Surfaces, " J. Chem. Phys., 107, 4033-4043 (1997).

2. Klier, K., "The C-H Bond Activation on Solid Surfaces: Stretching, Cracking, Tunneling and Control," Keynote Lecture at the Third European Congress on Catalysis (EUROPCAT-III), Krakow, Poland (September 1997).

3. Park, K. T., Klier, K., Wang, C. B., and Zhang, W. X., "Interaction of Tetrachoroethylene with $\operatorname{Pd}(100)$ Studied by High Resolution X-Ray Photoemission Spectroscopy," J. Phys. Chem., 101, 5420-5428 (1997).

4. Park, K. T., Herman, R. G., and Klier, K., "Adsorption of Pentamethylcyclopentasiloxane on the $\operatorname{Pd}(100)$ Surface Studied by High Resolution X-Ray Photoemission Spectroscopy," Surface Sci., 417, L1125-L1132 (1998).

5. Hunsicker, R A., Klier, K., and Herman, R. G., "Dissociative Chemisorption of Pentamethylcyclopentasiloxane on a Palladium Foil," under revision and to be submitted.

6. Simmons, G. W., Angst, D. L., and Klier, K., "A Self-Modeling Approach to the Resolution of XPS Spectra into Surface and Bulk Components," J. Electron Spectrosc. Relat. Phenom. (1999); in press.

7. Hunsicker, R. A., Klier, K., and Simmons, G. W., "XPS Resolution of Bulk and Surface Palladium Species by Self-Modeling of Angle Resolved Spectra of Palladium Foil after Pentamethylcyclopentasiloxane Adsorption," under revision and to be submitted.

8. Wang, Y.-N., Marcos, J. A., Simmons, G. W., and Klier, K., "Adsorption of Dichloromethane and Its Interaction with Oxygen on the Pd(100) Surface: Effect of Chlorine Layers on Oxygen Chemisorption and Oxidation of Carbon Residues, " I. Phys. Chem., 94, 7597-7607 (1990). 
9. Gürer, E. and Klier, K., "Structural Determination of a Palladium Single Crystal Using Photoelectron and Auger-Electron Angular Distributions," Phys. Rev. B, 46, 4884-4890 (1992).

10. Park, K. T., Simmons, G. W., and Klier, K., "Oxygen-induced Surface Core-level Shift and Angle-resolved X-Ray Photoemission Spectroscopy of c(2x2)O/Pd(100)," Surface Sci., 367 3070-320 (1996).

11. Klier, K., Simmons, G. W., Park, K. T., Wang, Y.-N., Hess, J. S., and Herman, R. G., "Ensemble Effects in the Oxygen/Chlorine/Pd(100) System, " Langmuir, 14, 13841391 (1998).

12. Hess, J. S., "Fundamental Interactions at Selected Catalyst Surfaces: Methane/ Palladium, Oxygen/Palladium, and Cesium/Molybdenum Disulfide," Ph.D. Dissertation, Department of Chemistry, Lehigh University (1998); K. Klier, advisor.

13. Park, K. T., Richards-Babb, M., Freund, M. S., Weiss, J., and Klier, K., "Surface Structure of Single-Crystal $\mathrm{MoS}_{2}(0002)$ and $\mathrm{Cs} / \mathrm{MoS}_{2}(0002)$ by X-ray Photoelectron Diffraction," J. Phys. Chem., 100, 10739-10745 (1996).

14. Park, K. T., Richards-Babb, M., Hess, J. S., Weiss, J., and Klier, K., "Valence-band Electronic Structure of $\mathrm{MoS}_{2}$ and $\mathrm{Cs} / \mathrm{MoS}_{2}(0002)$ Studied by Angle-resolved X-ray Photoemission Spectroscopy," Phys. Rev. B, 54, 5471-5479 (1996).

15. Park, K. T., Hess, J. S., and Klier, K., "Electron Transfer Reactions on $\mathrm{Cs} / \mathrm{MoS}_{2}(0002)$ with Chlorine, Oxygen, and Water: High Resolution X-Ray Photoelectron Spectroscopy and Theoretical Study," J. Chem. Phys., 111, 1636-1649 (1999).

16. Park, K. T., Klier, K., et al., "Electron Transfer and Redox Reactions on $\mathrm{Li} / \mathrm{MoS}_{2}(0002)$ with Chlorine, Oxygen, and Water: High Resolution X-Ray Photoelectron Spectroscopy and Theoretical Study," under revision and to be submitted. 


\section{Junior Personnel Working on this Project:}

Kenneth T. Park was the post-doctoral research associate working on this project. He is now an Assistant Professor of physics at Baylor University in Waco, TX.

James S. Hess was a graduate student working on this project. He received his Ph.D. in Chemistry in May 1998 and is now a post-doctoral research associate in the Department of Chemistry at the University of Delaware in Newark, DE.

Robert A. Hunsicker was a graduate student working on this project. He will receive the M.S. degree in Chemical Engineering in October 1999.

Andrew P. Butler was an undergraduate student who assisted in the computational modeling and theoretical analyses that were carried out. He received the B.S. degree in Chemistry in May 1999. 